\title{
PRÁTICAS DE ENSINO DA LEITURA E FORMAÇÃO DE PROFESSORES: CONTRIBUIÇÕES DO PNAIC
}

\section{PRACTICES OF READING TEACHING AND TEACHER TRAINING: PNAIC CONTRIBUTIONS}

\author{
Nathália Cristina Amorim Tamaio de Souza ${ }^{1}$
}

\begin{abstract}
Resumo: O ensino da leitura costuma ser tema recorrente no âmbito dos programas de formação continuada de professores. Contudo, os modos de mediação da aprendizagem da leitura continuam sendo alvo de tensões na área, uma vez que as bases desse trabalho nem sempre convergem. Muitas vezes, concebe-se a ideia de leitura como decodificação de palavras, enquanto, em outros casos, a ênfase concentra-se na mobilização de estratégias cognitivas. Pensando nisso, e defendendo a segunda abordagem, este artigo objetiva analisar as contribuições do PNAIC no que se refere às práticas de ensino da leitura, considerando como fontes geradoras de dados os registros de Orientadores de Estudo que acompanharam os Professores Alfabetizadores, em 2015, e os cadernos de formação disponibilizados no mesmo ano. Tais materiais foram apreciados à luz da perspectiva sociocultural e revelaram aspectos positivos quanto à incorporação e à ressignificação dos conhecimentos relacionados à leitura pelos professores participantes do programa.
\end{abstract}

Palavras-chave: Ensino da leitura; formação docente; PNAIC.

\begin{abstract}
The teaching of reading is usually a recurring theme in the context of continuing education programs for teachers. However, the modes of mediation of learning to read continue to be the subject of tensions in the area, since the bases of this work do not always converge. Often, the idea of reading is conceived as word decoding, while in other cases, the emphasis is on mobilizing cognitive strategies. With this in mind, and defending the second approach, this article aims to analyze the contributions of the PNAIC with regard to reading teaching practices, considering as sources of data the records of Study Counselors who accompanied the Literacy Teachers in 2015, and the training books made available in the same year. Such materials were appreciated in the light of the sociocultural perspective and revealed positive aspects regarding the incorporation and re-signification of knowledge related to reading by the teachers participating in the program.
\end{abstract}

Keywords: Teaching of reading; teacher training; PNAIC.

\section{Introdução}

Muito se tem estudado sobre leitura, ressaltando-se sua importância no processo de aquisição do conhecimento historicamente produzido. Assim como escrever, ler é uma atividade essencial para a vida em sociedade e, nesse caminho de aprendizagem da leitura que, geralmente, se inicia nos primeiros anos de escolarização -, a figura do professor apresenta-se como um verdadeiro divisor de águas. Isso porque, a abordagem, o método e a perspectiva de ensino da leitura que consubstanciam as práticas docentes determinam, em grande medida, a relação que os estudantes estabelecerão com o hábito de ler.

De acordo com Kleiman (1989), o contexto escolar tende a não favorecer a atividade de leitura, visto que nele, muitas vezes, esta baseia-se em procedimentos de decodificação e constitui-se apenas em um pretexto para cópias e outras atividades relacionadas à língua. Essa

\footnotetext{
${ }^{1}$ Universidade Estadual de Campinas (UNICAMP).
} 
postura, nas palavras da autora, faz com que o estudante perca-se em relação aos objetivos da leitura, começando a ler "sem ter ideia de onde quer chegar, e, portanto, a questão de como irá chegar lá (isto é, das estratégias de leitura) nem sequer se põe” (KLEIMAN, 1989, p. 30).

Diante desse cenário, a necessidade de uma formação que oportunize ao professor ensinar a leitura com base na seleção de textos autênticos, integrais e diversificados, faz-se urgente. Formação essa em que a mediação docente seja orientada para que os alunos aprendam modos de ler que lhes permitam entender que o sentido do texto não é um resultado automático da relação entre grafemas e suas correspondências sonoras, e que o propósito da leitura reside nela mesma.

Posto isso, neste antigo propõe-se analisar as contribuições de uma iniciativa de formação de professores, o Pacto Nacional pela Alfabetização na Idade Certa (PNAIC) ${ }^{2}$, no que tange às práticas de ensino de leitura nos anos iniciais do Ensino Fundamental, considerando-se como fontes de dados os registros de trinta e dois Orientadores de Estudo (OEs) na plataforma Moodle ao longo das formações conduzidas em 2015 no município de São Paulo. Também optou-se por consultar os cadernos de formação utilizados no mesmo ano (mais precisamente os cadernos 2 - "A criança no ciclo de alfabetização"; 4 - "A organização do trabalho escolar e os recursos didáticos na alfabetização"; e 5 - A oralidade, a leitura e a escrita no ciclo de alfabetização"), visto que esse material reúne uma série de orientações teórico-práticas sobre o processo de ensino-aprendizagem da leitura. Para nortear a análise empreendida, as seguintes questões foram formuladas: A formação oferecida pelo PNAIC contribui favoravelmente para as práticas de ensino da leitura nos anos iniciais do Ensino Fundamental? Se sim, quais são os principais indícios dessa contribuição?

As respostas a tais questões serão diluídas nas seções a seguir, as quais estão sequenciadas conforme a seguinte disposição: Na primeira seção, intitulada "Concepções de leitura e a formação continuada de professores", serão discutidas algumas considerações oriundas de estudos no referido campo de pesquisa; na segunda seção, nomeada "Práticas de ensino da leitura no âmbito do PNAIC" serão explicitados e analisados os dados emergentes do material eleito sob a égide da perspectiva sociocultural; e, nas Considerações Finais, apresentar-se-á uma síntese acerca das contribuições do PNAIC às práticas de ensino de leitura.

\section{Concepções de leitura e a formação continuada de professores}

A temática 'leitura' é algo que pode ser observado através de, pelo menos, duas lentes absolutamente distintas. A primeira corresponde à ideia de aquisição de um código baseado na relação entre grafemas e fonemas que permita ao sujeito decodificar textos escritos. Nessa concepção, enfocando-se especificamente o contexto escolar, os textos apresentados são, na maioria das vezes, desconectados da realidade do sujeito em questão (neste caso, o aluno), já que os materiais selecionados para leitura não estabelecem, necessariamente, relação com aqueles que circulam em ambientes externos à escola. Além disso, nesse tipo de leitura os alunos passam a focar sua atenção na decifração das palavras, sem direcionarem a leitura à construção de sentidos e sem interagirem com os textos (TERZI, 1995).

A segunda concepção de leitura, de forma antagônica à perspectiva acima descrita, concebe a leitura a partir de pontos de vista mais enunciativos, defendendo que seu ensino deve considerar o uso de textos que se relacionem à vida cotidiana do aluno. Esse modo de enxergar a leitura considera aspectos de natureza metacognitiva, tais como o estabelecimento de objetivos e a formulação de hipóteses, os quais "se opõe aos automatismos e mecanicismos

\footnotetext{
2 As reflexões aqui tecidas sobre o PNAIC referem-se, especificamente, ao trabalho desenvolvido sob responsabilidade institucional da UNESP, nas dependências da Escola de Formação e Aperfeiçoamento de Professores (EFAP), no município de São Paulo.
} 
típicos do passar do olho que muitas vezes é tido como leitura na escola" (KLEIMAN, 1989, p. 44). Uma leitura que requer, portanto, estratégias.

Solé (1998) defende que as estratégias de leitura são passíveis de serem ensinadas, sugerindo que o trabalho com textos em meio escolar envolva situações didáticas em que os alunos sejam incitados a usar diferentes formas de relação entre textos. Brandão e Rosa (2010) acreditam que essas estratégias podem ser ativadas já nos anos iniciais de escolarização, através, por exemplo, de rodas de conversa sobre textos.

Outro aspecto que merece atenção ao se discutir práticas de leitura na escola, na perspectiva sociocultural, diz respeito às finalidades da leitura. Ler para compor um repertório comum; ler para comentar/argumentar sobre o que foi lido; ler para se entreter (leitura deleite); ler para aprender a ressignificar; ler para partilhar textos que apreciamos: são diversas as possibilidades e os objetivos da leitura. Objetivos esses que se diferenciam daqueles estritamente pedagógicos, pois ainda que saber ler seja condição essencial para a realização de tarefas escolares, concentrar os objetivos da leitura nesse fim seria limitar a experiência leitora. Desse modo, ao refletirmos sobre as finalidades da leitura, é importante levarmos em conta que ler é um diálogo que:

(...) sempre começa com uma pergunta que fazemos a um texto, não importa que essa pergunta seja para nos distrair, para nos emocionar, para nos confortar, para esquecer, para lembrar, para identificar ou para compartilhar. Se a leitura é um diálogo, todo diálogo começa essencialmente com uma pergunta, com uma questão, cuja resposta nos leva a outra pergunta e a outra resposta e a outra pergunta... (COSSON, 2014, p. 4).

Conceber a leitura desse modo muda expressivamente a forma de arquitetar e de organizar o ensino. É preciso contribuir para que os alunos criem estratégias de leitura e percebam a finalidade do ato de ler, considerando a presença de elementos de determinados textos em outros textos e em situações vivenciadas cotidianamente. Isso significa dizer que:

o leitor - um sujeito que atua socialmente, construindo experiências e história - compreende o que está escrito a partir das relações que estabelece entre as informações do texto e seus conhecimentos de mundo. Ou seja, o leitor é sujeito ativo do processo. Na leitura, não age apenas decodificando, isto é, juntando letras, sílabas, palavras, frases, porque ler é muito mais do que apenas decodificar. Ler é atribuir sentidos. E, ao compreender o texto como um todo coerente, o leitor pode ser capaz de refletir sobre ele, de criticá-lo, de saber como usá-lo em sua vida (CAFIERO, 2010, p. 86).

Nessa perspectiva de relações e usos que interligam experiências escolares e extra escolares, a leitura alinha-se ao que conhecemos por 'letramento'.

Embora as pesquisas sobre o ensino da leitura nos anos iniciais do Ensino Fundamental e o discurso de professores alfabetizadores endossem a importância de assumirmos uma ação voltada ao princípio do letramento, não é raro nos depararmos com relatos de experiência que denotem práticas que permanecem inclinadas à decodificação de textos e à fragmentação das palavras. Ao que parece, mesmo os professores transparecendo aderência ao letramento, sentem que fazer a transposição do conceito em contextos práticos de ensino da leitura é um desafio.

No tocante a essa questão, vale mencionar o volume intitulado "Preciso 'ensinar' o letramento? Não basta aprender e ler e a escrever?", da coleção "Linguagem e letramento em foco", organizada pelo Centro de Formação de Professores do Instituto de Estudos da Linguagem (Cefiel) em parceria com o Ministério da Educação (MEC), no qual a autora Angela Kleiman, dirigindo-se 
especialmente a professores, elucida aspectos diretamente relacionados ao ensino. Na visão da autora, dificuldades para exercer o ensino na direção do letramento fundam-se ao concebê-lo como aquilo que ele não é: um método; um tipo alfabetização; uma habilidade. O letramento é, na verdade, uma prática sociocultural de uso da língua escrita (KLEIMAN, 2005, p. 19) e, como tal, revela-se nas minúcias do fazer cotidiano, nos eventos de letramento ${ }^{3}$ oportunizados.

Na obra em referência, Kleiman (2005) salienta que as facetas dos usos da escrita que são relevantes para o trabalho com leitura, tendo como pano de fundo o conceito de letramento, têm sido negligenciadas na formação do professor. Desse modo, e considerando a significativa aderência de professores ao Pacto Nacional Pela Alfabetização na Idade Certa (PNAIC), cabe questionar: Será que as formações conduzidas pelo programa também negligenciam tais facetas, ou contribuem, de algum modo, para a constituição de práticas de ensino da leitura favoráveis? Responder a esta questão é o que pretende a próxima seção.

\section{Práticas de ensino da leitura no âmbito do PNAIC}

Este estudo pretende investigar, a partir da perspectiva de trinta e dois Orientadores de Estudo (OEs) participantes do PNAIC em 2015 e do conteúdo dos cadernos de formação número 2, 4 e 5, as contribuições do curso de formação continuada oferecido pelo programa para as práticas de ensino da leitura nos anos iniciais do Ensino Fundamental.

A fim de atender aos objetivos delineados, recorreu-se a registros dos OEs na plataforma Moodle. O recurso da plataforma foi utilizado ao longo das atividades de formação, a fim de que os participantes pudessem tecer seus comentários acerca do que haviam aprendido, multiplicado $^{4}$ e percebido nas práticas de ensino dos Professores Alfabetizadores (PAs).

Cumpre enfatizar que todos os trinta e dois OEs - cujos nomes aqui citados são fictícios, a fim de assegurar o princípio do anonimato - adequaram-se aos seguintes critérios para que seus registros fossem incorporados a este estudo: participaram do programa no ano anterior (2014); têm formação em Pedagogia (a maioria também já havia cursado o magistério); atuavam há mais de cinco anos em suas respectivas Diretorias de Ensino do município de São Paulo; tiveram frequência superior a $75 \%$ nos encontros presenciais de formação. Esses critérios foram de suma relevância, pois representaram requisitos essenciais para que expectativas promissoras quanto à multiplicação das ações formativas fossem projetadas.

Partindo para o estudo dos registros em si, foi possível identificar que os OEs levantaram aspectos sobre: a) as principais dificuldades dos PAs para ensinar a leitura nos anos iniciais; b) algumas possibilidades do PNAIC para a superação das dificuldades elencadas; e, por fim, c) o que se leva da experiência no PNAIC. Assim, os trechos selecionados dos registros seguirão essa sequência para sua apreciação.

\section{a) As principais dificuldades dos PAs para ensinar a leitura nos anos iniciais}

Trecho 1, OE Mariana: As duas maiores dificuldades dos alunos que mais "pesam" para as PAs que observei foram a leitura e a interpretação. Pudemos verificar o quanto a leitura

\footnotetext{
${ }^{3}$ De acordo com Kleiman (2005, p. 23), "um evento de letramento inclui atividades que têm as características de outras atividades da vida social: envolve mais de um participante e os envolvidos têm diferentes saberes [...] é um evento essencialmente colaborativo".

${ }^{4} \mathrm{O}$ termo em referência faz alusão à característica multiplicadora do PNAIC, em que formadores conduzem as formações aos OEs, e os OEs as "repassam" / "replicam" / "reconduzem" aos PAs, que, finalmente, as colocam em ação no "chão da escola".
} 
interfere na interpretação e vice-versa. Os alunos não dominando uma leitura fluente, a interpretação fica prejudicada.

Trecho 2, OE Rosa: Na Leitura uma das maiores dificuldades encontrada é quanto ao ensino da fluência leitora e compreensão do que se lê.

Trecho 3, OE Marta: Vejo que existem algumas dificuldades marcantes, que são dos alunos, mas afetam os professores por não saberem exatamente como melhorar: ler com certa fluência e inferir informações implícitas e até mesmo explícitas no texto.

Trecho 4, OE Suely: no que se refere à Leitura, a grande dificuldade se encontra em Ler com compreensão, uma vez que apenas a decodificação não garante que a leitura assuma a sua principal função, a social.

Os trechos acima foram selecionados, dentre os trinta e dois disponíveis, porque sintetizam aspectos revelados de forma unânime no que se refere às dificuldades enfrentadas pelos PAs ao ensinarem a leitura, quais sejam: a interpretação, a fluência, a inferência, a antecipação de informações, a leitura dotada de sentido (compreensão do que se lê).

Se considerarmos o exposto na seção anterior, que descreve brevemente algumas concepções de leitura e suas relações com a formação de professores, notaremos que os aspectos levantados pelas OEs são, de fato, esperados. Isso porque Kleiman (2005) já vinha sinalizando a permanência de práticas de decodificação e os empasses para o trabalho na perspectiva do letramento, denotando que professores tendem a ensinar a leitura de textos de forma fragmentada e com objetivos incoerentes. Se o aluno não imagina a leitura como algo que pode ser prazeroso, encantador, libertador, dificilmente se entregará à imersão no texto e tampouco lerá com fluência ou terá compreensão sobre o que leu; dificilmente entenderá que um texto apresenta sentidos para além da junção de sílabas que formas palavras e mais palavras. $\mathrm{O}$ mesmo raciocínio se aplica às dificuldades para fazer inferências e produzir sentidos, pois estas são habilidades provenientes de estratégias de leitura e, uma vez que tais estratégias são suprimidas pelo aligeiramento da leitura e pela ausência de aprofundamento do texto, o entendimento daquilo que foi lido deixa de cumprir seu papel. Nesse sentido, faz-se imperioso resgatar o que Kleiman adverte sobre o ato de ler:

O mero passar de olhos pela linha não é leitura, pois a leitura implica uma atividade de procura pelo leitor, no seu passado de lembranças e conhecimentos, daqueles que são relevantes à compreensão de um texto que fornece pistas e sugere caminhos, mas que certamente não explicita tudo o que seria possível explicitar. (KLEIMAN, 1989, p. 26-27).

Na citação, a autora é enfática ao afirmar que uma leitura superficial não é leitura. Pelo menos não o tipo de leitura desejável para que sejam mobilizados fatores como: a busca por alguma coisa que a leitura irá revelar; o acionamento de conhecimentos prévios que permitem identificar o real sentido, explícito ou não, em um texto; o levantamento de hipóteses que os caminhos do texto possibilitam criar para o desfecho que está por vir.

No caderno número 5 do material formativo do PNAIC (BRASIL, 2015c), intitulado "A oralidade, leitura e a escrita no Ciclo de Alfabetização", Leal e Rosa (2015) apontam que uma prática usual nas escolas é solicitar que as crianças leiam em voz alta para serem avaliadas quanto à fluência na oralização do texto escrito. Valendo-se da percepção de Colomer (2007), as autoras defendem que "essa leitura tenha como objetivo a constituição 
de repertórios comuns e que gere a oportunidade não somente de trocar diferentes opiniões, mas de se atentar para o fato de que os processos de significação são ao mesmo tempo individuais e coletivos" (LEAL; ROSA, 2015, p. 33).

Desse modo, é possível depreender que as dificuldades das PAs se deram em função do desencontro entre ensino da leitura e as finalidades e estratégias de ativação cognitiva inerentes ao processo. Deslocar o objetivo pedagógico para os objetivos da leitura, atendo-se às especificidades dessa atividade poderia ser um modo mais assertivo de conduzir o importante e complexo papel de ensiná-la.

\section{b) Algumas possibilidades do PNAIC para a superação das dificuldades elencadas}

Trecho 1, OE Paula: A postura que tomamos foi a constituição coletiva de práticas que possibilitem ao aluno aprender a partir da diversidade de textos que circulam socialmente (jornais, revistas, manuais de instruções, revistas em quadrinhos, textos informativos, e-mails etc.). O professor tem a importante tarefa de propiciar aos seus alunos a diversidade de texto que todos têm direito, de modo que a leitura e a escrita sejam desenvolvidas numa linguagem real, natural, significativa e vivenciada.

Trecho 2, OE Silvia: Para a leitura, nossa proposta foi colocar os alunos em contato permanente com textos de circulação social, através da leitura em voz alta, da leitura compartilhada, da leitura deleite, da leitura de ajuste, da leitura silenciosa, acompanhada ou não da compreensão do texto, cruzadinhas com ou sem banco de palavras, do estímulo aos procedimentos leitores de acordo com a finalidade da proposta de leitura. A cada semana é sorteado um aluno para fazer a leitura deleite de outra sala, assim levam os livros para casa, escolhem a leitura, treinam e, no dia marcado, realizam a leitura para os alunos da sala sorteada para receber o leitor.

Trecho 3, OE Marta: Na leitura nos organizamos para algumas ações: Antecipar a informação que segue no texto; - Verificar se o que foi antecipado se confirma ou não; - Reler para compreender melhor; - Inferir informações implícitas no texto coletivamente (contando com a colaboração de cada aluno). Os professores planejam atividades permanentes, sequenciadas e projetos que inserem as crianças em processos de interação, para desenvolver as habilidades acima descritas. Para isso, utilizam jogos, acervo de livros do PNAIC, diferentes suportes de textos e uma diversidade de gêneros textuais. $O$ bom planejamento, replanejamento, o uso de materiais diversificados presentes na sala de aula assim como a intervenção e mediação do professor estão fazendo com que os alunos se apropriem de comportamentos leitores e escritores.

Trecho 4, OE Cíntia: As escolas procuraram desenvolver a habilidade leitora dos alunos com bastante envolvimento dos livros do pacto e com estratégias bastante significativas para os alunos, envolvendo-os e instigando para o conhecimento do mundo letrado. Várias ações foram feitas no município para a melhoria da capacidade leitora, como: sarau de poesias, leituras compartilhadas, dramatizações de textos em oficinas e brincadeiras. A criança brinca de faz. de conta que está lendo antes mesmo de entrar na escola, e não devemos deixar que este desejo que acontece com ela desde muito pequena se perca ao chegar à escola. Não devemos deixar que a leitura se torne um martírio para as crianças.

Se uma única palavra pudesse definir as colocações dos OEs neste bloco, seria, sem dúvida, a palavra 'diversidade'. Diversidade de textos; diversidade de suportes de textos; 
diversidade de tipos de leitura; diversidade de eventos de letramento; diversidade de gêneros textuais; diversidade de materiais; diversidade de atividades. Ao que parece, as professoras encontram caminhos comuns e profícuos, apropriando-se das orientações formativas do PNAIC para efetuarem mudanças nas práticas de ensino da leitura.

Além da diversidade em si, ficou bastante clara a busca por finalidades para cada situação proposta: para o tipo de leitura (em voz alta, silenciosa, compartilhada), para o tipo de texto (quanto ao gênero, ao suporte e ao papel social que reflete) e esse é um indício altamente promissor, que revela a potencialidade do PNAIC para a superação - ou, ao menos, a minimização - de dificuldades que vinham se instalando há anos nas escolas. Esse engajamento, tanto dos OEs através da formação e do acompanhamento, como dos PAs, pela realização efetiva em sala de aula, revelam uma faceta do letramento sem a qual o trabalho nessa perspectiva seria inviável: a colaboração. Conforme já aludido neste texto, Kleiman cita os eventos de letramento como algo que se faz necessário para que práticas de letramento se concretizem. Em tais eventos, os participantes envolvidos "têm diferentes saberes, que são mobilizados na medida adequada, no momento necessário, em prol de interesses, intenções e objetivos individuais e de metas comuns" (KLEIMAN, 2005, p. 23). Se tal condição se aplica aos alunos, na construção cotidiana de conhecimentos mediados pela leitura, aplica-se também aos profissionais da educação que, ao se articularem colaborativamente e tendo objetivos comuns a serem perseguidos, produzem resultados melhores.

Ainda na perspectiva do letramento, sublinha-se a busca, pelos professores, de textos que circulem no meio social das crianças, com a finalidade de aproximar o pequeno leitor do universo letrado. Essa preocupação traduz um olhar especial para a atribuição de sentidos de um texto, presente no caderno de formação número 5 (BRASIL, 2015c). A incitação a práticas de ensino que considerem o contexto real do aluno, seus conhecimentos prévios, suas afinidades e familiaridades é algo que se defende com afinco nesse caderno, destacando-se o caráter favorável dessa opção para a aproximação do aluno com os textos.

O caderno número 2 (BRASIL, 2015a), nomeado "A criança no ciclo de alfabetização", e o caderno número 4 (BRASIL, 2015b), que carrega o título "A organização do trabalho escolar e os recursos didáticos na alfabetização", advogam que nos primeiros anos do Ensino Fundamental, é fundamental que o ensino da leitura e da escrita esteja articulado a momentos de brincadeiras e de exploração de outras linguagens. Nessa direção, os trechos de registros das OEs Marta e Cíntia revelam total coerência ao mencionarem que foram explorados jogos e brincadeiras durante as práticas de ensino da leitura. Trabalhar na perspectiva da ludicidade é muito importante, haja vista que o brincar é uma atividade inerente à infância. Portanto, estabelecer essa relação entre leitura e brincadeira pode gerar uma atmosfera mais convidativa para a aprendizagem.

Por fim, outra apropriação interessante que foi lembrada em diferentes registros é a prática da leitura deleite. Muito estimulada em todos os cadernos formativos do PNAIC, bem como nos cursos ministrados, a leitura deleite é compreendida como um dos tipos de leitura que mais evidencia que seu objetivo deve centrar-se nela mesma. Como o próprio nome 'deleite' sugere, esse tipo de leitura significa entretenimento, encanto, agrado, e, assim sendo, não escancara um objetivo pedagógico que se relacione à aprendizagem de um conteúdo, por exemplo, fazendo com que as crianças apreciem o momento.

Um balanço geral sobre este bloco permite inferir que a formação oferecida pelo PNAIC é uma potente aliada para o professor rever e repensar suas práticas de ensino da leitura. Embora os alcances da proposta tenham também suas limitações, que se devem em ao largo espaçamento entre um período de formação e outro, acredita-se que sua característica multiplicadora seja capaz de atingir um número expressivo de educadores, influenciando positivamente seus modos de fazer. 


\section{c) O que se leva da experiência no PNAIC}

Trecho 1, OE Paula: Aprendemos que a leitura é conteúdo em si mesmo e precisa ser abraçado pela escola como tal. [...] A escola precisa despertar na criança o prazer pela leitura. A tarefa não é fácil, é um elo que se forma: o professor precisa ter prazer pela leitura para despertar este prazer no aluno.

Trecho 2, OE Luciana: Com relação a leitura foram desenvolvidas formações que privilegiaram a importância de compreendê-la como um conteúdo, como uma atividade complexa e que o conhecimento da natureza da leitura, o conhecimento dos procedimentos $e$ estratégias de leitura utilizados pelos leitores proficientes, o reconhecimento de si (professor) como leitor proficiente e o agir como leitor proficiente são chaves fundamentais para a formação de leitores.

Trecho 3, OE Amanda: O que mais prevaleceu foi a força de vontade e o carinho que os professores desenvolveram em sala de aula com as estratégias propostas no pacto. Esse envolvimento e esse movimento da formação fizeram toda a diferença no âmbito escolar, pois quem lê bastante $e$ fluentemente escreve com bastante facilidade. O bom leitor é um bom escritor!

Este último bloco apresenta-se com o intuito de 'selar' as discussões empreendidas ao longo do texto, e, para isso, pareceu oportuno acrescentar os registros dos OEs sobre o que se leva da experiência no PNAIC. De acordo com os eles, a mudança de olhares foi um fator determinante. Mudar a forma de compreender as especificidades e a complexidade do ensino da leitura, bem como revisitar e rever seus próprios conceitos sobre o ensino representou uma das facetas mais notáveis ao final do ciclo de formação. Nessa direção, pode-se dizer que o registro da OE Paula reuniu, em poucas palavras, objetivos essenciais da formação: aprender que a leitura é conteúdo em si mesmo e que despertar o gosto do aluno pela leitura requer que, primeiramente, o professor se veja como alguém que gosta de ler.

Para complementar e finalizar esse mote, destaca-se o registro da OE Luciana, o qual enfatiza que o reconhecimento de si (professor) como leitor proficiente e o agir como leitor proficiente são chaves fundamentais para a formação de leitores. Tal percepção revela-se um verdadeiro combustível para os professores que, muitas vezes, mesmo trabalhando cotidianamente com o ensino da leitura, esquecem-se como leitores.

\section{Considerações finais}

Chegar às considerações finais de um texto remete ao resgate das proposições e inquietações que lhe deram origem. Assim, faz-se válido responder, finalmente, às questões: A formação oferecida pelo PNAIC contribui favoravelmente para as práticas de ensino da leitura nos anos iniciais do Ensino Fundamental? Se sim, quais são os principais indícios dessa contribuição?

Diante do explicitado no decorrer deste artigo, pôde-se perceber que a formação oferecida pelo PNAIC, de fato, contribui num sentido positivo para que práticas de ensino da leitura sejam repensadas e ressignificadas (no contexto do PNAIC/UNESP/São Paulo). E, mais do que isso: na perspectiva do letramento. Com relação aos indícios, vale citar o reconhecimento da mudança de olhares dos OEs e, consequentemente, dos PAs sobre os modos de ensinar a leitura; a apropriação de estratégias, finalidades e especificidades da leitura; a intencionalidade nos momentos de escolha dos tipos de leitura a serem explorados, bem como dos suportes e dos gêneros textuais; a validação da ludicidade, especialmente na fase de descobrimento da leitura; 
a organização do trabalho pedagógico de modo que os eventos de letramento sejam favorecidos; o trabalho colaborativo; o reconhecimento do professor como leitor e o investimento no hábito da leitura, a fim de que o gosto do aluno pelo ato de ler seja naturalmente incentivado.

Embora a literatura da área confira certo descrédito aos programas de formação continuada - e o fazem com razão -, o PNAIC, ao que parece, destaca-se em alguns pontos, como a qualidade dos textos, cuja autoria inclina-se aos pressupostos socioculturais aqui defendidos; sua alta abrangência e movimento de adesão; as expectativas dos professores, geralmente positivas em relação ao curso; a produção bibliográfica nacional sobre os alcances no programa em diferentes esferas. Nesse sentido, espera-se que as ações do programa, com seu poder multiplicador, permaneçam motivando perspectivas otimistas para as práticas de ensino dos professores alfabetizadores.

\section{Referências}

BRANDÃO, Ana Carolina Perrusi; ROSA, Ester Calland de Sousa. A leitura de textos literários na sala de aula: é conversando que a gente se entende. In: PAIVA, Aparecida; MACIEL, Francisca; COSSON, Rildo (Org.). Coleção Explorando o Ensino: Literatura - Ensino Fundamental. v. 20. Brasília: SEB/ MEC, 2010. p. 69-106.

BRASIL. Pacto Nacional pela Alfabetização na Idade Certa. A criança no ciclo de alfabetização. Caderno 02. Brasília: MEC, SEB, 2015a.

BRASIL. Pacto Nacional pela Alfabetização na Idade Certa. A organização do trabalho escolar e os recursos didáticos na alfabetização. Caderno 04. Brasília: MEC, SEB, 2015 b.

BRASIL. Pacto Nacional pela Alfabetização na Idade Certa. A oralidade, a leitura e a escrita no Ciclo de Alfabetização. Caderno 05. Brasília: MEC, SEB, 2015c.

CAFIERO, Delaine. Letramento e leitura: formando leitores críticos. In: RANGEL, Egon de Oliveira; ROJO, Roxane Helena Rodrigues (Org.). Coleção Explorando o Ensino: Língua Portuguesa - Ensino Fundamental. v. 19, p. 85-106, Brasília: SEB/ MEC, 2010.

COLOMER, Teresa. Andar entre livros: a leitura literária na escola. São Paulo: Global, 2007.

COSSON, Rildo. Círculos de leitura e letramento literário. São Paulo: Contexto, 2014.

KLEIMAN, Angela. Texto e leitor: aspectos cognitivos da leitura. São Paulo: Pontes, 1989

KLEIMAN, Angela. Preciso "ensinar" o letramento? Não basta ensinar a ler e a escrever? Cefiel/ IEL/Unicamp, 2005.

LEAL, Telma Ferraz; ROSA, Ester Calland de Sousa. Formação de leitores na escola: leitura como prática social. In: BRASIL. Pacto Nacional pela Alfabetização na Idade Certa. A oralidade, a leitura e a escrita no Ciclo de Alfabetização. Caderno 05. Brasília: MEC, SEB, 2015c.

SOLÉ, Isabel. Estratégias de leitura. Porto Alegre: Artes Médicas, 1998.

TERZI, Sylvia. A construção da leitura. Campinas: Pontes, 1995. 


\section{Sobre a autora}

Nathália Cristina Amorim Tamaio de Souza é Pedagoga e Mestra em Educação Escolar pela UNESP e Doutoranda em Educação na UNICAMP, com bolsa CNPq, vinculada ao grupo de estudos ALLE/AULA. Trabalha como docente de Educação Básica (anos iniciais do Ensino Fundamental) na Escola SESI de Araraquara e atua como pesquisadora no grupo GEPFEC da UNESP.

E-mail: nathytamaio@ hotmail.com. 